\title{
Rapid and simple screening of transgenic mice: novel extraction-free, filter-based PCR genotyping from blood samples
}

\author{
Naoya Suematsu and Fumihide Isohashi ${ }^{\circledR}$ \\ Department of Biochemistry, St. Marianna University School of Medicine, Kanagawa, Japan; \\ 凶e-mail:n2sue@marianna-u.ac.jp
}

Received: 10 April, 2006; revised: 01 June, 2006; accepted: 27 June, 2006

available on-line: 02 September, 2006

\begin{abstract}
We evaluated the effectiveness of using Flinders Technology Associates (FTA) filter paper for the polymerase chain reaction (PCR) genotyping of transgenic mice. Tail prick blood sample dried on an FTA filter disc was processed for genomic PCR. It is easy and rapid to prepare DNA templates because the protocol is extraction-free and only requires minimal handling of wash briefly bloodstained FTA filter discs. Progeny of a transgene-positive founder mated with wild-type mice was screened for the presence of the transgene by the filter-based PCR using transgene-specific primers. The resulting amplicons with expected sizes of $3134 \mathrm{bp}, 1152 \mathrm{bp}, 877 \mathrm{bp}$ and $688 \mathrm{bp}$ were robust and reproducible, allowing a distinction between transgenic $(n=44)$ and wild-type $(n=47)$ mice showing no signal. The filter-based PCR screening took only half a day. The present study

confirmed the validity and usefulness of the novel rapid extraction-free genotyping method.
\end{abstract}

Keywords: PCR genotyping, transgenic mice, FTA filter paper, blood samples, cytosolic acetyl-CoA hydrolase

\section{INTRODUCTION}

To date, genomic DNA extraction from tail biopsies has been routinely employed in genotyping transgenic mice (Conner, 2005). However, it is timeconsuming (2 days) and troublesome to digest biopsy fragments overnight followed by hours of DNA extraction.

We describe here a much simpler and useful method of extraction-free PCR genotyping from small volume of blood instead of biopsy samples. The protocol takes only half a day using commercially available FTA filter paper (Whatman Japan KK). The filter is recently used for collection, distribution and long-term storage of a wide variety of wildlife samples for DNA analysis, including animals (Smith \& Burgoyne, 2004) and plants (Tsukaya et al., 2005). It is also used for surveillance and detection of a variety of pathogens, including protozoa (Gonzales et al., 2006), bacteria (Liu et al., 2005) and viruses (Ndunguru et al., 2005). Further, in genetic studies on human population and identification, it is used for sampling human materials such as blood (Seah et al., 2003), buccal epithelial cells (Salvador et al., 2004), and casualty remains (Fujita \& Kubo, 2006).

FTA filter is a cellulose membrane containing lyophilized chemicals that lyse cell membranes and denature proteins. In the case of blood samples, the nuclear DNA released from blood cells is physically entrapped within the matrix of the paper, where the DNA remains stable at room temperature for more than 14 years (unpublished observations in Whatman data sheet) against attacking agents such as nucleases, oxidants, UV and microorganisms (Seah \& Burgoyne, 2000). It has been established that mouse blood samples spotted on the FTA filter can be directly used as a template for PCR (Smith \& Burgoyne, 2004) as well as PCR-based Southern blotting (Hsiao et al., 1999). RNA species on FTA filter were also used as templates for real-time RT-PCR (Ndunguru et al., 2005). FTA filter now offers the most reliable choice for extraction-free PCR genotyping of

Abbreviations: $\mathrm{CACH}$, cytosolic acetyl-CoA hydrolase; FTA, Flinders Technology Associates; PCR, polymerase chain reaction; SAP, serum amyloid P component. Enzyme: acetyl-CoA hydrolase (EC 3.1.2.1). 
transgenic mice from only a small volume of blood samples instead of conventional tail biopsies.

\section{MATERIALS AND METHODS}

Mice. A CACH-transgenic mouse C57BL/6N$\operatorname{TgN}(S A P-h C A C H)$ was generated (Macrogen Inc., Seoul, Korea) by zygote microinjection of the transgene presented in Fig. 1A. Wild-type C57BL/6N inbred mice were from Clea Japan Inc. (Tokyo, Japan) and our own colony. The transgenic progeny was maintained as heterozygotes by crossing transgene carriers with the same C57BL/6N strain wildtype mice. The F1-F4 generations were genetically screened for the transgene at 3-4 weeks of age. Mice were fed food and water ad libitum. Animal care was in accordance with the national guidelines for animal experimentation.

Blood samples. Tail prick whole blood samples $(<5 \mu \mathrm{L}$ each) obtained under ether anesthesia were spotted onto FTA filter papers (Whatman Japan KK). The bloodstained filters were allowed to dry completely for $1 \mathrm{~h}$ at room temp. before being punched cleanly. For sample processing, two discs were manually punched from each bloodstained filter with a Harris Micro-Punch fitted with a 1.2-mm steel tip, and were placed one-by-one in sterile 200$\mu \mathrm{L}$ PCR microcentrifuge tubes. To prevent crosscontamination between samples, the puncher was cleaned by taking one punch from an unspotted area of the filter paper. Each bloodstained disc $1.2 \mathrm{~mm}$ in diameter was subsequently subjected to a brief series of washes carried out in the PCR tube according to the manufacturer's instructions (Whatman Japan KK), with impurities being washed away and the DNA being entangled within the discs. Briefly, the sample discs were washed twice in $200 \mu \mathrm{L}$ of mild buffer (Whatman FTA purification reagent) and then rinsed once in $200 \mu \mathrm{L}$ of DNase-free water by 1-min incubation at room temp. The washes were discarded after each centrifugation at $12000 \times g$ for $10 \mathrm{~s}$. The resultant genomic DNA-loaded discs were white and now ready for downstream PCR analysis.

PCR genotyping. The processed sample disc was then placed directly in $20-\mu \mathrm{L}$ genomic PCR mixture containing $300 \mathrm{pM}$ of each primer, $2.5 \mathrm{mM}$ of each dNTP, $2.5 \mathrm{mM}$ magnesium chloride, $20 \mathrm{mM}$ Tris/HCl buffer ( $\mathrm{pH} 8.0$ ) and $1 \mathrm{U}$ LA Taq polymerase $(\mathrm{TaKaRa})$. Transgene-specific primers used were listed in Table 1, and the targeted bands are represented in Fig. 1B. PCR conditions were as follows: denaturation at $94^{\circ} \mathrm{C}$ for $5 \mathrm{~min}$ followed by 35 cycles of $98^{\circ} \mathrm{C}$ for $10 \mathrm{~s}$, annealing at $58^{\circ} \mathrm{C}$ for $1 \mathrm{~min}$ and extension at $72^{\circ} \mathrm{C}$ for $3 \mathrm{~min} 10 \mathrm{~s}$, followed by a final extension at $72^{\circ} \mathrm{C}$ for $5 \mathrm{~min}$. PCR products were separated by agarose gel electrophoresis using 1.5\% SeaKem ${ }^{\circledR}$ GTG agarose (TaKaRa) and then visualized by ethidium bromide staining for typing analysis. High DNA Mass ${ }^{\mathrm{TM}}$ Ladder (Gibco BRL) and 100 bp DNA Ladder (Invitrogen) were used.

\section{RESULTS AND DISCUSSION}

PCR products with expected sizes were successfully amplified from the sample discs as well as from a plasmid containing the transgene (not shown). The filter-based PCR using a primer pair of S1/A3 (Fig. 1B) amplified a large product with the expected size of $3134 \mathrm{bp}$ (Fig. 2), while the PCR using three pairs of S1/A1, S2/A2 and S3/A3 (Fig. 1B) resulted in the expected 688-bp, 877-bp and 1152-bp products (Fig. 2). Although genotyping primers are conventionally designed for amplifying relatively small products (from about 150 to $500 \mathrm{bp}$ ) to ensure that the reaction is robust (Conner, 2005), all of the four larger products were robustly amplified (Fig.

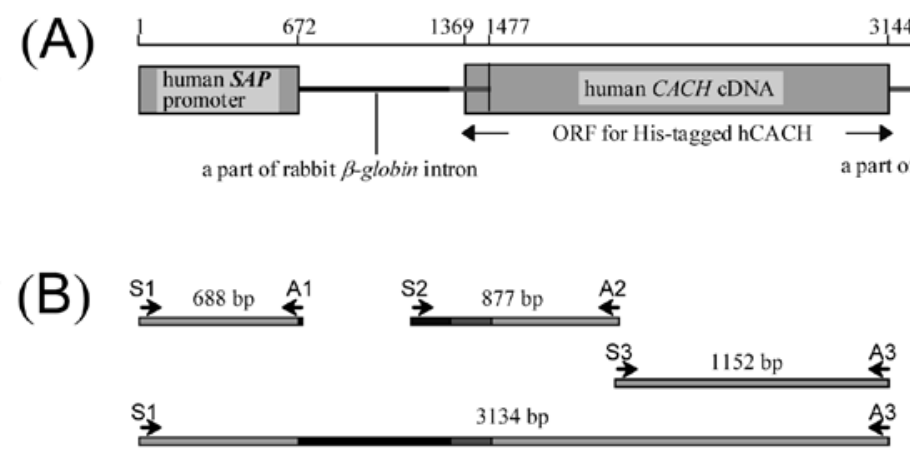

Figure 1. Schematic depiction of PCR strategy for detection of a transgene.

(A) The transgene construct used for generation of CACH-transgenic mice. Human serum amyloid P component (SAP) promoter was ligated to the ORF of His-tagged human cytosolic acetyl-CoA hydrolase (CACH) (Isohashi et al., 1984; Suematsu et al., 2002) via a part of rabbit $\beta$-globin intron. Human SAP promoter can direct liver-specific expression after birth. Numbers mark nucleotide positions. (B) Lines show four DNA fragments targeted for PCR amplification. Arrows indicate the location and orientation of four genotyping primer pairs used (Table 1). 
Table 1. Genotyping primers used.

Nucleotide positions are numbered as in Fig. 1A. Human specific coding sequences distinct from those of mouse are highlighted in bold type. S, sense; A, antisense; CDS, coding sequence.

\begin{tabular}{lllll}
\hline Primer & \multicolumn{1}{c}{ Sequence $\left(5^{\prime}-3^{\prime}\right)$} & Length $(\mathrm{mer})$ & Tm $\left({ }^{\circ} \mathrm{C}\right)$ & Position \\
\hline S1 & TAGAGCTTCATGGGGACAGAAAG & 23 & 58.7 & $2 / 24$ \\
S2 & CATCCTGGTCATCATCCTGCC & 21 & 60.4 & $1131 / 1151$ \\
S3 & GATGAAGAGGAGGAGCGGTTC & 23 & 60.5 & $1984 / 2006$ \\
A1 & CTGAAGTTCTCAGGATCCTCTAGG & 24 & 60.5 & $689 / 666$ \\
A2 & GGAAACCGCTCCTTCCTCTTC & 21 & 60.4 & $2007 / 1987$ \\
A3 & GCTTACAAACCCATCATCAGGAGG & 24 & 60.5 & $3135 / 3112$ \\
\hline
\end{tabular}

2), showing high effectiveness of the filter-based PCR genotyping. Further, the amplified 3134-bp product (Fig. 2), which covers extensively the promoter and the full-length ORF (Fig. 1), demonstrated that the transgene was stably integrated without rearrangement or partial deletion observed in some cases of transferring genes. Of all the progeny ( $\mathrm{n}=$ 91) analyzed, the FTA filter-based PCR genotyping provided successful distinction between the transgenic carrier $(\mathrm{n}=44)$ showing a strong signal and wild type $(n=47)$ showing no signal (Fig. 2$)$. The proportion of the confirmed transgenic carrier $(48 \%)$

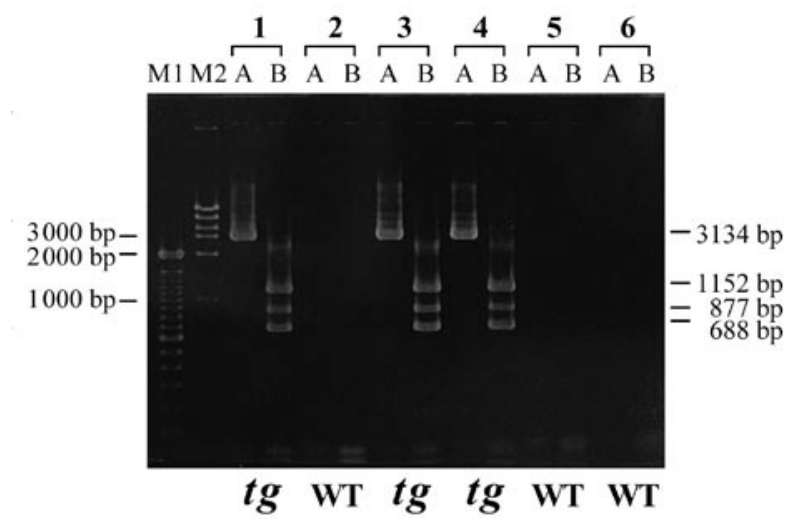

Figure 2. Typical examples of PCR genotyping for detection of a transgene from mouse whole blood samples spotted on FTA filter paper.

Genomic DNA retained on a 1.2-mm FTA disc was used as a template for a $20-\mu \mathrm{L}$ PCR reaction. Two microliters of amplified sample was loaded and electrophoresed on a $1.5 \%$ SeaKem GTG agarose gel followed by ethidium bromide staining. Samples 1-6 were from six F3 offspring. Lanes denoted A contain PCR products using the primer pair S1/A3, while lanes denoted B contain those using three primer pairs S1/A1, S2/A2 and S3/A3 (Fig. 1B). Expected sizes of amplicons obtained with primer pairs S1/ A1, S2/A2, S3/A3 or S1/A3 are 688 bp, 877 bp, 1152 bp or $3134 \mathrm{bp}$, respectively, as indicated on the right. The lane denoted M1 contains a 100-bp DNA ladder composed of 15 blunt-ended fragments between 100 and $1500 \mathrm{bp}$ in multiples of $100 \mathrm{bp}$ and an additional fragment at 2072 bp, and M2 contains High DNA Mass ${ }^{\mathrm{TM}}$ composed of equimolar mixture of six DNA fragments of 10000, 6000, 4000, 3000, 2000 and 1000 bp. Samples 1, 3 and 4 were judged to represent transgenic genotype $(t g)$, while samples 2, 5 and 6 were judged to represent wild type (WT). appears well with the predicted Mendelian frequency, revealing that the transgene has been stably integrated and transmitted. Although not only PCR but also Southern blotting is widely used for screening transgenic mice, PCR is generally accepted as a method of choice because of its simplicity and sensitivity (Conner, 2005). Therefore, genetic screening strategy using the filter-based PCR described here is probably the best method to use at this stage.

In the present paper, we extend the utility of FTA filter to routine PCR genotyping of transgenic mice. We have demonstrated here the effectiveness of the rapid PCR genotyping using FTA filter from minute intravenous blood samples. The novel method eases the animals' pain by circumventing conventional tail biopsy, and saves a lot of labor for genomic DNA extraction inevitable in conventional genetic screening employed to date in labs worldwide. Thus, the extraction-free, filter-based genotyping from very small amounts of blood is recommended as a standard tool for genetic identification in routine studies using transgenic mice as well as in other genotyping or mutation analyses.

\section{Acknowledgements}

This research was supported by a grant from the Vitamin Society of Japan.

\section{REFERENCES}

Conner DA (2005) In Current Protocols in Molecular Biology (Ausubel FM, Brent R, Kingston RE, Moore DD, Seidman JG, Smith JA, Struhl K, eds) pp 23.10.1-23.10.8. John Wiley \& Sons, Inc., USA.

Fujita Y, Kubo S (2006) Leg Med (Tokyo) 8: 43-47.

Gonzales JL, Loza A, Chacon E (2006) Vet Parasitol 136: 119-126.

Hsiao KM, Lin HM, Pan H, Li TC, Chen SS, Jou SB, Chiu YL, Wu MF, Lin CC, Li SY (1999) J Clin Lab Anal 13: 188-193.

Isohashi F, Nakanishi Y, Matsunaga T, Sakamoto Y (1984) Eur J Biochem 142: 177-181.

Liu JW, Zhang W, He JP, Zhou W, Yuan YW (2005) Sheng Wu Gong Cheng Xue Bao 21: 1009-1013.

Ndunguru J, Taylor NJ, Yadav J, Aly H, Legg JP, Aveling T, Thompson G, Fauquet CM (2005) Virol J 2: 45-56. 
Salvador JM, Corazon M, De Ungria A (2004) Oral Oncol 40: 231-232.

Seah LH, Burgoyne LA (2000) In Progress in Forensic Genetics (Sensabaugh GF, Lincoln PJ, Olaisen B, eds) 8, pp 74-77. Elsevier, Amsterdam.

Seah LH, Jeevan NH, Othman MI, Jaya P, Ooi YS, Wong PC, Kee SS (2003) Forensic Sci Int 138: 134-137.
Smith LM, Burgoyne LA (2004) BMC Ecol 4: 4-14.

Suematsu N, Okamoto K, Isohashi F (2002) Acta Biochim Polon 49: 937-945.

Tsukaya H, Iokawa Y, Kondo M, Ohba H (2005) J Plant Res 118: 57-60. 